\title{
REGIME POLÍTICO E CRESCIMENTO ECONÔMICO DOS ESTADOS E SEUS IMPACTOS NO COMPORTAMENTO DOS GASTOS MILITARES NO SÉCULO XXI (2000-2019)
}

Thomas ferdinand heye ${ }^{1}$ e André Vilarin de Lima²

\begin{abstract}
RESUMO: Esta pesquisa analisa os dados de 92 países com níveis distintos de desenvolvimento econômico e tipo de regime político para testar as hipóteses levantadas acerca da influência de fatores da esfera doméstica dos Estados no comportamento dos gastos militares no século XXI (anos 2000 a 2019). Utilizando como método de pesquisa a política comparada, apoiada em técnicas de análise quantitativa, os resultados obtidos pela Correlação de Pearson indicam uma correlação alta e positiva entre as variáveis média de variação de gastos e média de variação de PIB e uma correlação alta e negativa entre as variáveis média de variação de gastos e indicador de regime, validando as hipóteses levantadas. Desta forma, os resultados contribuem para o esforço de outros autores em investigar o impacto econômico e de tipo de regime político como fatores fundamentais que impactam no comportamento dos gastos militares dos Estados.
\end{abstract}

Palavras-chave: Gastos militares. Economia de Defesa. Democracia. Crescimento econômico. Produto Interno Bruto. Estudos Estratégicos. Segurança Internacional

ABSTRACT: This research analyzes data from 92 countries with different economic development levels and type of regime in order to verify and validate the hypotheses about the influence of the state domestic factors (political and economic) in the military spending behavior in the 21st century (years 2000 to 2019). Taking the comparative policy as a research method, supported by quantitative analysis techniques, the outcomes obtained by Pearson's Correlation indicate a high and positive correlation between the average variables of expenditure variation and the average of GDP variation and a high and negative correlation between the average variables of expenditure variation and regime indicator, confirming the hypotheses. In this way, the outcomes have contributed to the next authors' researches by proving that the type of political regime is a fundamental factor that influences the state military expenditure behavior and reinforces studies of the economic factors' influence on military expenditures' behavior.

Keywords: Military expenditures. Defense Economics. Democracy. Economic growth. Gross Domestic Product. Strategic Studies. International Security.

\footnotetext{
${ }^{1}$ Doutor em Ciência Política. Professor do Programa de Pós-Graduação em Estudos Estratégicos da Defesa e Segurança (PPGEST/INEST)

${ }^{2}$ Centro de Instrução Almirante Sylvio de Camargo (CIASC).
} 


\section{INTRODUÇÃO}

Em 2019 os gastos militares alcançaram os níveis mais altos desde o fim da Guerra Fria, na ordem de US\$1.917 bilhões, sendo 3,6\% maior do que em 2018. Os gastos militares per capita teve crescimento de $2,47 \%$ (de US $\$ 243$ para US $\$ 249$ ) em 2019 , mesmo ano em que o aumento populacional de $1,1 \%$ foi superado pelo aumento de $3,3 \%$ dos gastos militares mundiais3. Esses dados foram o ponto de partida para uma investigação do comportamento dos gastos militares no século atual.

No século XXI é possível observar uma alteração no comportamento dos gastos militares desde o fim da Guerra Fria. Se logo após a dissolução da antiga União das Repúblicas Socialistas Soviéticas (URSS)4 e o fim das tensões entre as duas grandes potência (EUA e URSS), verificou-se um forte declínio dos gastos militares, no século XXI é iniciada uma ascensão dos gastos militares mundiais, chegando em 2019 a valores mais altos desde o fim da Guerra Fria.

Apesar da forte pressão de setores da sociedade de que os Estados deveriam reduzir seus gastos com defesa, redirecionando estes recursos para áreas de desenvolvimento social por exemplo, o que observamos é uma tendência de incremento de gastos com defesa a cada ano.

Neste artigo analisaremos a influência de dois fatores presentes na esfera doméstica dos Estados: um político, analisando a influência do grau de democracia, e o outro econômico, onde será analisada a influência do crescimento econômico, expresso na variação do valor do Produto Interno Bruto (PIB), no comportamento dos gastos militares. Para tanto, foram formuladas duas hipóteses de comportamento dos gastos militares. Para testá-las, recorremos à análise estatística de dados de 92 países para o período dos anos 2000 até 2019

Em suma, o artigo pretende contribuir para o esforço de pesquisa entre o tipo de regime político, democracia e sua influência no comportamento dos gastos militares dos Estados. Neste sentido, analisamos a correlação entre o tipo de regime e a variação dos gastos militares no século XXI. Ademais, incluímos também fatores

\footnotetext{
${ }^{3}$ Fonte de dados: Stockholm International Peace Research Institute (SIPRI). Trends in world military expenditure, 2019. April, 2020.

${ }^{4}$ A URSS se dissolveu oficialmente em 31 de dezembro de 1991, após 69 anos de existência.
} 


\section{Universidade Federal Fluminense \\ Instituto de Estudos Estratégicos}

econômicos, analisando a correlação da variação dos gastos militares com a variação do PIB dos países entre 2000 a 2009

Em relação à literatura de apoio a esta pesquisa, destacamos, inicialmente, que Goldsmith (2003) realizou uma extensa análise na busca do entendimento da causa de uns Estados gastarem mais em defesa do que outros. Este autor analisou diversos fatores internos e externos para um longo período, de 1886 até 1989, testando diversas hipóteses. O autor constata em sua análise que os fatores crescimento econômico e tipo de regime político tem uma forte relação com o comportamento dos gastos militares. Ademais, Goldsmith (2003, p.567) verifica que ao longo dos 104 anos analisados, alguns fatores que anteriormente acreditava-se ter forte influência nos gastos militares, não apresentaram uma relação robusta com estes, como os fatores de países em guerra civil, guerras entre Estados e rivalidades latentes.

Heye (2005) envidou um grande esforço para compreender o comportamento heterogêneo dos gastos militares no pós-Guerra Fria, incluindo fatores da esfera doméstica dos Estados, como o tipo de regime, democracia, e relações civis-militares, juntamente com outros fatores (conflitos externos, principais potências, produto interno bruto, renda per capita e conflitos internos), abrangendo o período de 1990 a 1998, quando se observou um forte declínio dos gastos militares mundiais agregados, concluindo o autor que "fatores políticos domésticos possuem uma influência substancial nos gastos militares" (p.121).

Sua grande contribuição foi a inclusão da variável relações civis-militares e seus impactos nos gastos militares: "a relevância deste tópico encontra-se no fato de que para as novas democracias dos anos 90, o princípio de controle civil sobre o poder militar irá se revelar fundamental em relação aos gastos militares." (Heye, 2015, p.121). De fato, como demonstrado em seu estudo, ministérios de defesa ocupados por titulares civis provocam o efeito de redução nos gastos militares, ou seja: "conforme a nossa expectativa, esta variável apresentou o sinal negativo esperado e revelou-se significativa." (Heye, 2015, p.121). Ainda, este autor confirmou ainda a expectativa de que no período do pós-Guerra Fria a democracia levaria os países a gastarem menos com defesa: "no que se refere à dimensão política, a perspectiva otimista para a redução dos gastos militares no pós-Guerra Fria acreditava que a nova ordem mundial 
liberal seria mais pacífica" (p.14). Seu estudo chegou a valores significativos de redução nos gastos militares em relação à variável independente democracia: "Se durante o século XX o aumento de uma unidade na escala de democracia do polity IV representa um decréscimo de $0.002 \%$ nos gastos militares, nos anos 90 o mesmo aumento representará uma diminuição de 0.035\% nos gastos militares” (Heye, 2015, p.120).

Em relação aos estudos da influência do PIB dos Estados no comportamento dos gastos militares, verificou-se um incremento substancial com o aumento do PIB: "De acordo com os coeficientes obtidos, o crescimento de 1\% do Produto Interno Bruto acarreta no aumento de $0.70 \%$ dos gastos militares no período do pós-Guerra Fria" (Heye, 2015, p.120). O resultado positivo era esperado pelo autor, porém o elevado acréscimo foi surpreendente:

"Conforme a nossa expectativa, esta variável apresentou o sinal positivo esperado e se revelou significativa [..]. Entretanto, no nosso modelo esta variável revelou um efeito substantivo extremamente elevado." (Heye, 2015, p.120).

Yildirim e Sezgin (2005) analisaram empiricamente os dados de 92 países para o período de 1987 a 1997, a fim de verificar se existe uma relação negativa entre o grau de democracia e os gastos de defesa. A hipótese foi elaborada a partir de uma análise minuciosa entre as relações de democracia, paz e gastos militares, verificando que os países democráticos preferem resolver seus conflitos de forma pacífica, com mais diálogo, reduzindo assim as tensões entre os Estados e promovendo uma sensação de paz:

"Em um Estado democrático, os conflitos são resolvidos por acordos e meios não violentos, que proporcionam um ambiente em que os conflitos internacionais entre Estados democráticos também sejam resolvidos pacificamente"5 (p.94).

Os resultados de suas análises os levaram a concluir que quanto maior o nível de democracia menores serão os gastos militares, e afirmam ainda que o aumento dos níveis de democracia levaria a um mundo mais pacífico: "Assim, as tentativas em todo o mundo de aumentar o nível da democracia podem resultar em mundo mais

\footnotetext{
${ }^{5}$ Tradução própria do texto original: "In a democratic state, domestic conflicts are resolved by compromise and nonviolent means, which provide an environment where international conflicts between democratic states are also settled peacefully."
} 


\section{Universidade Federal Fluminense \\ Instituto de Estudos Estratégicos}

pacífico, reduzindo as despesas militares e, portanto, as guerras" 6 (YILDIRIM e SEZGIN, 2005, p.99).

Brauner (2014), examinou empiricamente se os gastos militares dos países democráticos são menores do que dos países autocráticos, utilizando um painel de 112 países no período de 1960 a 2000, procurando estimar um comportamento padrão para os gastos militares. $O$ autor concluiu que as democracias gastam um percentual do PIB menor do que as autocracias. Este autor demonstra forte preocupação com a qualidade dos dados utilizados em estudos anteriores, principalmente com os dados de gastos militares antes de 1988, onde cita que o próprio SIPRI afirma que os dados encontrados nos anuários anteriores a 1988 são inutilizáveis. O autor faz ainda uma análise da causualidade inversa para explicar os maiores gastos nas autocracias, de forma que não seriam os gastos militares maiores nas autocrácrias por causa do regime, e sim a manutenção do regime autocrático por causa dos altos gastos militares, que impedem uma transição de regime autoritário para o democrático. De acordo com Acemoglu, Ticchi e Vingini (2008, p. 4, apud BRAUNER, 2014, p. 5):

"Se a elite criar um exército poderoso para impedir a democratização,
então o exército também desempenha um papel importante na política
democrática até que seja reformada, e essa reforma não é instantânea.
Em particular, mostramos que, diante de um exército poderoso, um
regime democrático emergente precisará fazer grandes concessões
ou enfrentar uma alta probabilidade de um golpe. Essa ameaça de
golpe desaparece quando as forças armadas são reformadas. Curio-
samente, porém, é a antecipação de que os militares serão reforma-
dos assim que surge a oportunidade que dificulta o controle das forças
armadas durante o início das fases de um regime democrático - por-
que isso cria um problema de compromisso, tornando-o impossível
para governos democráticos fazer promessas credíveis para compen-
sar soldados por não tomarem ações contra a democracia "7.

\footnotetext{
${ }^{6}$ Tradução própria do texto original: "Thus worldwide attempts trying to increase the level of democracy may result in a more peaceful world, reducing military expenditures and hence wars."

${ }^{7}$ Tradução própria do texto original: "If the elite create a powerful military to prevent democratization, then the military also plays an important role in democratic politics until it is reformed, and such reform is not instantaneous. In particular, we show that faced with a powerful military, a newlyemerging democratic regime will either need to make costly concessions or face a high probability of a coup. This coup threat disappears once the military is reformed. Interestingly however, it is the anticipation that the military will be reformed as soon as the opportunity arises that makes it difficult to control the military during the early phases of a democratic regime - because this creates a commitment problem, making it impossible for democratic governments to make credible promises to compensate soldiers for not taking actions against democracy"
} 
Em relação a metodologia utilizada nesta pesquisa, destacamos que tratou-se de uma pesquisa exploratória, onde foram levantados dados e informações acerca dos níveis de democracia, do Produto Interno Bruto (PIB) e dos gastos militares de 92 países, tendo a finalidade de testar nossas hipóteses sobre a relação de fatores da esfera doméstica (as dimensões políticas e ecônomicas) dos Estados com os gastos militares no século XXI, validando ou não as hipóteses levantadas.

O método de pesquisa utilizado foi o de política comparada, devido à complexidade dos fenômenos sociais analisados e as variáveis envolvidas (democracia, produto interno bruto e gastos militares), apoiando-se em técnicas de análise de dados quantitativas, permitindo mensurar e testar as hipóteses.

De acordo com Arend Lijphart (1975, p. 03), a política comparada não tem um enfoque substantivo em si, mas sim metodológico. Para este autor, o método comparativo exige uma análise profunda dos dados por ter muitas variáveis envolvidos num universo pequeno. As dificuldades presentes neste método podem ser minimizadas, segundo Lijphart, aumentando os números de casos tanto quanto possível, reduzindo o "espaço-propriedade" da análise, dando enfoque na análise comparativa em caso "comparáveis" ou dando enfoque da análise comparativa nas variáveis-chave (p.08-14).

Nesta pesquisa procuramos aumentar o número de casos para o maior número possível de países, que apresentassem dados consistentes e passíveis de serem analisados, representando níveis distintos de desenvolvimento e de liberdade política, abrangendo todas as regiões do planeta.

A fonte utilizada para dados econômicos foi o Grupo Banco Mundial. Para os dados de gastos militares nos valemos da base elaborada pelo Stockholm International Peace Research Institute (SIPRI) e para os dados de regime polítco recorremos ao Center of Systemic Peace (Polity5). 


\section{Universidade Federal Fluminense}

Instituto de Estudos Estratégicos

\section{OS GASTOS MILITARES NO SÉCULO XXI}

Conforme explanado anteriormente, no ano de 2019 os gastos militares alcançaram os níveis mais altos desde o fim da Guerra Fria, na ordem de US $\$ 1.917$ bilhões, sendo 3,6\% maior do que em 2018. Os gastos militares per capita teve crescimento de $2,47 \%$ (de US $\$ 243$ para US $\$ 249$ ) em 2019 , mesmo ano que o aumento populacional de $1,1 \%$ foi superado pelo aumento de $3,3 \%$ dos gastos militares mundiais (ver gráfico 1). Esses dados foram o ponto de partida para uma investigação do comportamento dos gastos militares no século atual.

\section{Gráfico 1 - Crescimento dos gastos militares x crescimento populacional} no período de 2001 a 2019.8

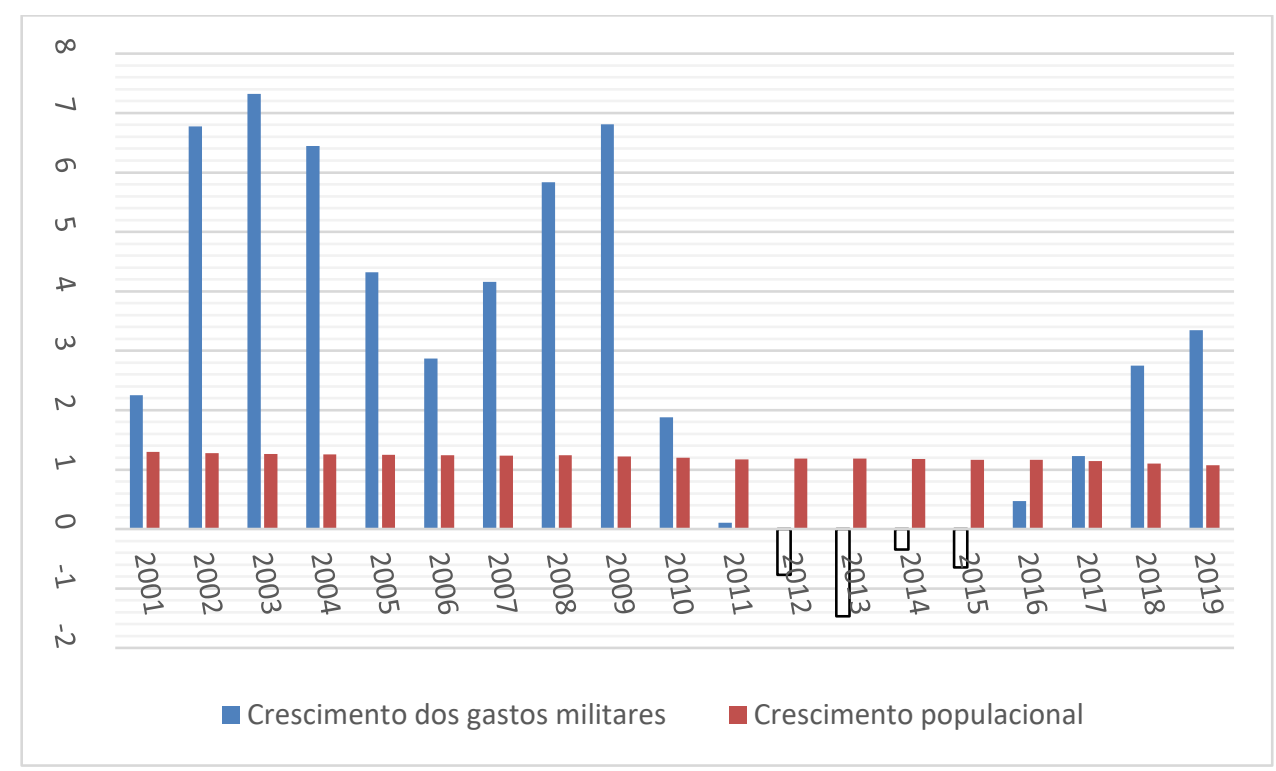

Logo após os atentados terroristas ocorridos no começo do século nos EUA, os gastos militares deram um salto de crescimento nos anos de 2002 a 2009 , tendo um crescimento médio de 5,56\%. Entretanto, a crise financeira de 2008 parece ter dado um freio neste robusto crescimento, pois nos anos seguintes, de 2010 e 2011 , o crescimento foi mais tímido, na média de 1,0\%, e sofrendo

\footnotetext{
${ }^{8}$ Gráfico elaborado pelo autor utilizando como fonte de dados: crescimento dos gastos militares - banco de dados do SIPRI; e crescimento populacional - banco de dados do Banco Mundial.
} 
uma recessão média de $-0,8 \%$ nos anos de 2012 a 2015, seguindo nova tendência de crescimento econômico entre 2016 e 2019.

Ao analisar a relação entre o crescimento dos gastos militares mundiais com o crescimento do PIB mundial, verifica-se que de 2001 a 2004 o crescimento dos gastos militares acompanha o aumento do PIB mundial, porém a forte queda no crescimento do PIB mundial do ano de 2007 a 2009 pode ter refletido na intensa queda nos gastos militares mundiais visto nos anos seguintes (2010 a 2015), voltando a ter crescimento somente a partir de 2016, quando já é observado uma estabilidade no crescimento do PIB mundial (ver gráfico 2).

\section{Gráfico 2 - Crescimento dos gastos militares $x$ crescimento do PIB mundial no período de 2001 a 2019.9}



No período dos anos 2000 a 2019, os 10 (dez) países que mais gastaram com defesa, em valores brutos, foram os Estados Unidos, China, Arabia Saudita, Reino Unido, França, Rússia, Índia, Japão, Alemanha e Coréia do Sul, que juntos representaram $77 \%$ (US $\$ 24,1$ trilhões) dos gastos militares mundiais (ver gráfico 3). Dos 10 (dez) países que mais gastaram com defesa, 4 (quatro) são membros da Organização do Tratado do Atlântico Norte (OTAN): EUA, Reino Unido, França e Alemanha. Juntos, esses 4 (quatro) foram responsáveis por 53\%

\footnotetext{
${ }^{9}$ Gráfico elaborado pelo autor utilizando como fonte de dados: crescimento dos gastos militares per capita -banco de dados do SIPRI; e crescimento do PIB - banco de dados do Banco Mundial.
} 


\section{Universidade Federal Fluminense \\ Instituto de Estudos Estratégicos}

(US\$ 16,6 trilhões) do total dos gastos militares mundiais. Os demais 6 (seis) países (Árabia Saudita, Rússia10, Índia, Japão e Coréia do Sul) estão localizados no continente asiático.

\section{Gráfico 3 - Os 10 (dez) países com maiores gastos militares no período de 2000 a 2019.11}

Gastos Militares 2000-2019 (US\$ tri)

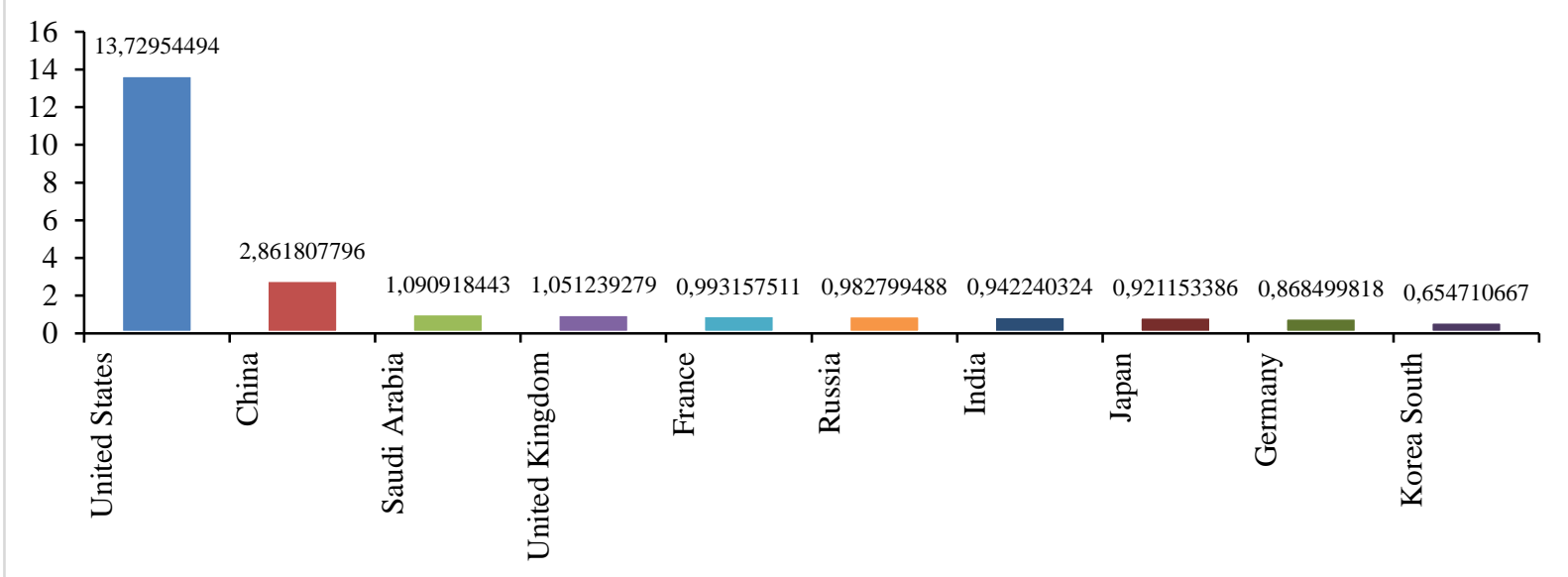

Podemos observar que dentre esses 10 (dez) países, 7 (sete) países (Estados Unidos, China, Japão, Alemanha, Reino Unido, França e Índia) estão entre os 10 (dez) países com maior PIB médio no período dos anos 2000 a 2019 (ver gráfico 4). Por estes dados, já se pode verificar a existência de uma relação entre gastos militares e PIB.

\footnotetext{
10 País transcontinental: território que se encontra em mais de um continente.

11 Gráfico elaborado pelos autores utilizando como fonte de dados o SIPRI.
} 
Gráfico 4 - Os 10 (dez) países com maiores PIB médio no período de 2000 a 2019.12

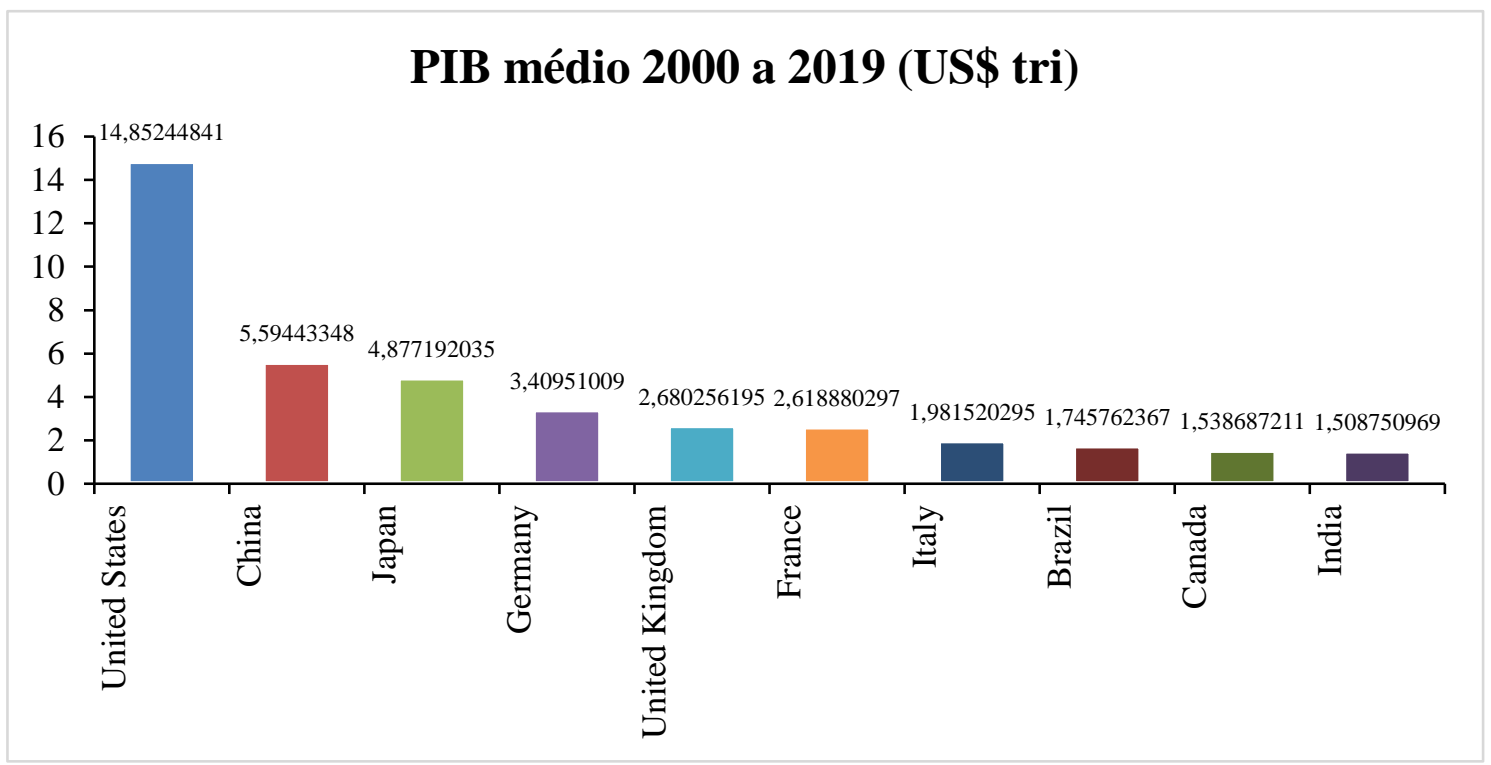

Analisando os gastos militares em termos de percentual do PIB, conhecido como fardo de defesa13, percebemos que no século XXI, os 10 (dez) países que tiveram os maiores gastos militares em relação ao seu PIB, em média, foram Arábia Saudita, Omã, Israel, Jordânia, Kuwait, Líbano, Argélia, Estados Unidos, Bahrein e Rússia (ver gráfico 5).

12 Gráfico elaborado pelos autores utilizando como fonte os dados do Banco Mundial.

13 Fardo de defesa (ou carga de defesa) é uma tradução para o termo em inglês defense burden, que representa a relação entre os gastos militares e o PIB. 


\section{Universidade Federal Fluminense \\ Instituto de Estudos Estratégicos}

Gráfico 5 - Os 10 (dez) países com maiores gastos militares em relação ao seu PIB.14

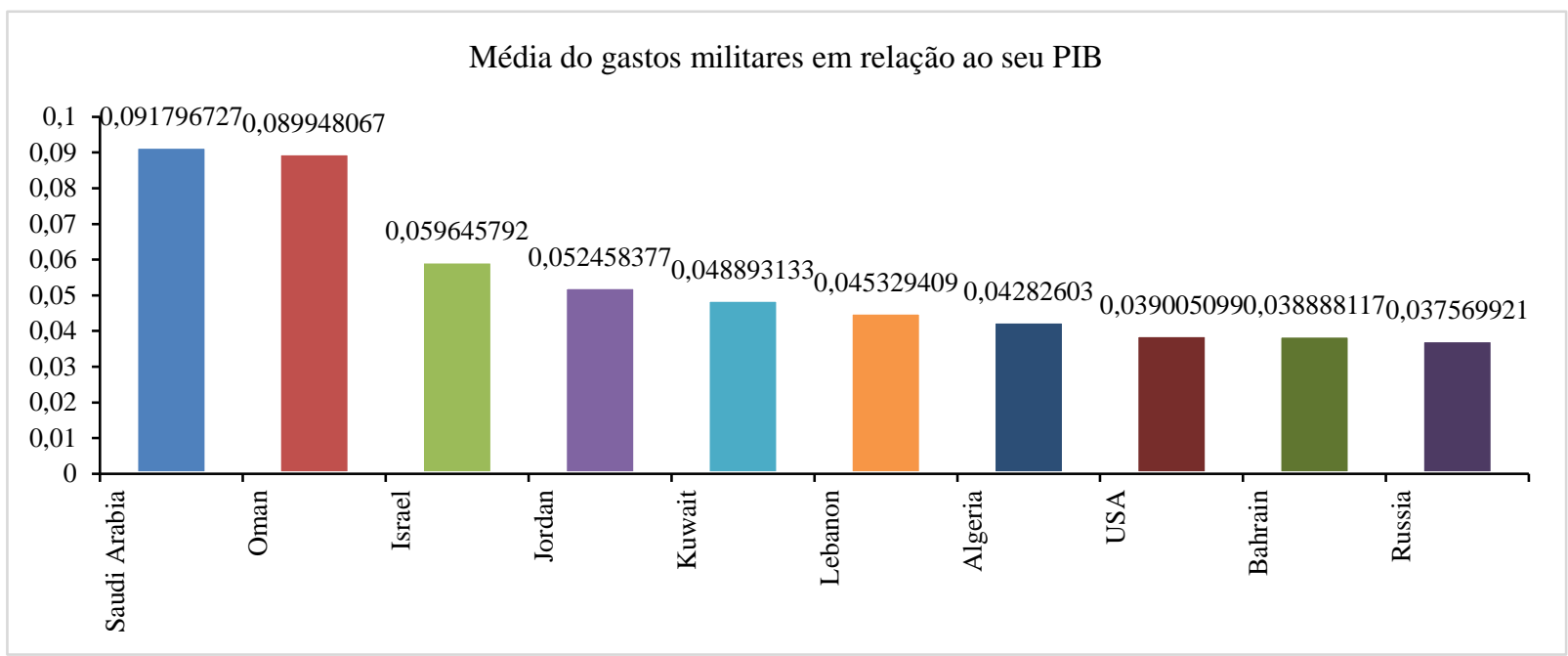

Podemos observar que dentre esses 10 (dez) países, somente um (Estados Unidos) está entre os 10 (dez) países com maior PIB médio no período dos anos 2000 a 2019. Percebe-se não haver forte relação entre o percentual do PIB gasto com defesa e a dimensão do PIB. Entretanto, deste mesmos 10 (dez) países, 4 (quatro) possuem índices negativos de democracia (Bahrein, Arábia Saudita, Omã e Kuwait) e 2 (dois) índices positivos baixos de democracia (Árgélia e Rússia). Nenhum desses 10 (dez) países possuem o índice mais alto de democracia.

\section{ANÁLISE DOS GASTOS MILITARES DO SÉCULO XXI}

Nesta seção serão apresentadas as hipóteses a serem testadas, envolvendo fatores da esfera doméstica (política e econômica) de 92 países e verificar a sua influência no comportamento dos gastos militares entre os anos de 2000 a 2019.

O cenário econômico internacional do século $X X I$ sofreu um forte impacto pela crise mundial de 2008. Países em todo o mundo, em menor ou maior grau,

\footnotetext{
${ }^{14}$ Gráfico elaborado pelo autor utilizando como fonte de dados: gastos militares em relação ao PIB banco de dados do SIPRI; e PIB - banco de dados do Banco Mundial.
} 
foram atingidos pela crise. Em 2009, pela primeira vez em décadas, a economia mundial se retraiu. Alguns países conseguiram se recuperar em pouco tempo, outros sofrem seus efeitos até os dias de hoje. A economia mundial que havia se expandido a taxa de $3 \%$ em 2008 , retraiu a taxa de $0,15 \%$, em 2009 . Este cenário reforça a importância na investigação da inclusão do impacto da variação do PIB nos gastos militares.

APrimavera Árabe15 iniciada em 2010 culminou com a queda de diversos governos autoritários no Oriente Médio e Norte da África. Contudo, muitos desses países ainda enfrentam forte instabilidade política. Ao longo do século XXI tivemos o estabelecimento de regimes democráticos em diversos países por toda a África e a continuação dos processos de transição e consolidação da democracia em países da Ásia Central, Europa Central e do Leste, assim como também na América do Sul. Como desdobramento, a investigação do impacto da democracia no comportamento dos gastos militares no século XXI se torna muito relevante.

\section{Crescimento econômico}

Tomando como base a literatura sobre a demanda por gastos militares que encontra-se na obra de Todd Sandler e Keith Hartley, The Economics of Defense (1995), o desempenho econômico de um país é um fator preponderante associado aos gastos militares. De acordo com Heye (2005, p. 84, apud SANDLER e HARTLEY, 1995, p. 61): “a razão para tanto decorre da premissa teórica realista de que Estados, ao obterem um aumento de sua riqueza, irão investir mais recursos em defesa." Goldsmith (2003) em sua extensa análise na busca do entendimento da causa de uns Estados gastarem mais em defesa do que outros, constatou que as variáveis crescimento econômico e riqueza tem uma forte relação com o aumento dos gastos militares, quando analisou diversos fatores internos e externos para o período de 1886 até 1989.

Nesta pesquisa, iremos avaliar a influência da variação do PIB na variação dos gastos militares ao longo do século XXI, pois entendemos que comparar

\footnotetext{
15 A Primavera Árabe se caracterizou por uma onda de protestos e revoluções ocorridas no Oriente Médio e norte do continente africano em que a população foi às ruas para derrubar ditadores, tendo iniciado na Tunísia em 2010.
} 


\section{Universidade Federal Fluminense \\ Instituto de Estudos Estratégicos}

valores brutos dos gastos militares de países com riquezas muito discrepantes, não daria uma informação precisa, pois os países mais ricos e desenvolvidos, dispondo de muito mais recursos financeiros para alocação em defesa poderão ter gastos brutos maiores com defesa, ainda que sua porcentagem de investimento do PIB em defesa seja menor. Neste sentido, iremos avaliar a variação dos gastos militares com a variação do PIB, verificando se um maior crescimento do PIB implica maiores ou menores incrementos dos gastos militares nos anos de 2000 a 2019.

Desta forma, tomando como base os estudos já realizados e resultados obtidos por outros autores, a nossa hipótese proposta para este fator é que: H1: quanto maior o crescimento do PIB do país, maiores serão os incrementos dos gastos militares.

\section{Democracia}

Ao analisar os determinantes dos gastos militares na busca do entendimento da causa de uns Estados gastarem mais em defesa do que outros, no período de 1886 a 1989, Goldsmith constatou que o tipo de regime tem uma forte relação com os gastos militares. Este autor concluiu que quanto mais democrático é um Estado, menor é o seu gasto militar. A explicação mais convincente para tal resultado, segundo Goldsmith, é a de que os eleitores em sua maioria preferem a aplicação de recursos financeiros em outros bens sociais em detrimento ao investimento em defesa, e os líderes que desejam permanecer no poder preocupam-se em atender as preferências dos eleitores.

Heye (2015), em seu esforço para compreender o comportamento heterogêneo dos gastos militares no pós-Guerra Fria incluindo fatores da esfera doméstica dos Estados, demonstrou em seus resultados que no período analisado a democracia levaria os países a gastarem menos com defesa. Conforme expectativa do próprio autor, seu estudo chegou a valores significativos de redução nos gastos militares em relação à variável independente democracia.

Yildirim e Sezgin ao analisarem empiricamente os dados de 92 países para o período de 1987 a 1997 chegaram a resultados que os levaram a concluir que quanto maior o nível de democracia menores serão os gastos militares. 
Brauner, examinando empiricamente se os gastos militares dos países democráticos são menores do que dos países autocráticos, utilizando um painel de até 112 países no período de 1960 a 2000, concluiu que as democracias gastam um percentual do PIB menor do que as autocracias.

Destarte, de acordo com os resultados obtidos por esses autores, somado ao cenário internacional do século $X X I$, foi adotada a seguinte hipótese em relação ao efeito de regimes democráticos nos gastos militares: $\mathrm{H} 2$ : quanto mais democrático for o país, menores serão os incrementos dos gastos militares.

Tabela 1 - Apresentação das hipóteses

H1 Quanto maior o crescimento do PIB do país, maiores serão os incrementos dos gastos militares

H2 Quanto mais democrático for país, menores serão os incrementos dos gastos militares

\subsection{SELEÇÃO DA BASE DE DADOS}

A seleção da base de dados procurou abranger o maior número possível de países, com níveis distintos de desenvolvimento econômico e tipo de regime, abarcando todas as regiões do planeta. Contudo, para termos uma base de dados consistente, incluir todos os países existentes se tornou impraticável pela limitação de dados confiáveis, ficando a base de dados com 92 (noventa e dois) países, conforme a tabela no anexo 1 , onde estão apresentadas ainda a variação percentual dos valores nominais em dólares norte-americanos a preços de 2018, exceto para o ano de 2019 , que está para o próprio ano, dos respectivos gastos militares e PIB para o período de 2000 a 2019.

\subsection{VARIÁVEL DEPENDENTE: GASTOS MILITARES}

Conforme mencionado anteriormente, o nosso estudo está focado em quanto o país aumentou ou diminuiu seus gastos militares entre 2000 e 2019, ou seja, na variação dos gastos militares. Desta forma, a nossa variável dependente consiste na variação percentual do valor nominal dos gastos militares em dólares norte-americanos a preços de 2018.

A nossa fonte é o SIPRI, que conforme informação de seu portal eletrônico 


\section{Universidade Federal Fluminense \\ Instituto de Estudos Estratégicos}

oficial, trata-se de "um instituto internacional independente dedicado à pesquisa de conflitos, armamentos, controle de armas e desarmamento". O SIPRI possui um banco de dados robusto, com excelente reputação internacional, sendo comumente utilizado em pesquisas relacionadas a gastos militares. O SIPRI fornece dados, análises e recomendações, com base em fontes abertas, se constituindo em ótima ferramenta para pesquisadores e demais públicos interessados.

\subsection{INDICADORES OPERACIONAIS DAS VARIÁVEIS INDEPENDENTES}

Variável independente: crescimento econômico

Esta variável está relacionada com a produção de riqueza de um país, mais especificamente no Produto Interno Bruto em valores nominais indexados aos preços de dólares norte-americanos e com valores constantes de 2019. Nosso foco foi na variação de riqueza do país, verificando se um maior aumento da riqueza proporciona também maior incremento dos gastos militares.

Desta forma, tomando ainda como base os estudos já realizados e resultados obtidos por outros autores, a nossa expectativa em relação a esta variável é que o crescimento econômico suscite um impacto positivo na variação dos gastos militares dos país.

A nossa fonte de dados dos valores do PIB nos anos de 2000 a 2019 para esta variável é o Grupo Banco Mundial, que possui atualmente 189 países membros, sendo uma parceria de cinco instituições que trabalham em prol da redução da pobreza e prosperidade nos países, principalmente fornecendo financiamento, consultoria sobre políticas e assistência técnica a governos de países em desenvolvimento.

Variável independente: democracia

Para estudar esta variável utilizamos o Polity5, que faz parte do The Polity Project do Center for Systemic Peace. O Polity5 continua a tradição de pesquisa do The Polity Project de codificar características de Estados no sistema 
internacional para fins de análise comparativa e quantitativa. O conjunto de dados do Polity5 cobre todos os principais Estados independentes no sistema global durante o período de 1800-2018 (ou seja, Estados com uma população total de 500.000 ou mais no ano de 2018; sendo 167 países). O esquema conceitual do Polity5 é único no sentido de que examina qualidades concomitantes de autoridade democrática e autocrática nas instituições de governo, em vez de formas de governança discretas e mutuamente exclusivas. Essa perspectiva prevê um espectro de autoridade governamental que abrange desde autocracias totalmente institucionalizadas, passando por regimes de autoridade mistos ou incoerentes (denominados "anocracias"), até democracias totalmente institucionalizadas.

O "Polity Score" captura esse espectro de autoridade do regime em uma escala de 21 pontos variando de -10 (monarquia hereditária) a +10 (democracia consolidada).

Conforme os resultados anteriormente por outros autores para períodos distintos, a nossa expectativa é de que no século $X X I$ o impacto de regimes democráticos na variação dos gastos militares seja negativo.

Tabela 2 - Estatística descritiva básica das variáveis

\begin{tabular}{|c|c|c|c|c|c|}
\hline & N & Mínimo & Máximo & Média & Erro Desvio \\
\hline Média Variação Gastos & 92 & $-1,58$ & 23,41 & 4,44 & 4,38 \\
\hline Indicador de Regime & 92 & -10 & 10 & 5,78 & 5,28 \\
\hline Média Variação PIB & 92 & 0,52 & 15,01 & 7,66 & 2,85 \\
\hline N válido (de lista) & 92 & & & & \\
\hline
\end{tabular}

\subsection{ANÁLISE ESTATÍSTICA DOS GASTOS MILITARES NO SÉCULO XXI}

Pretendemos avaliar a existência e o grau de correlação entre as duas variáveis em escalas intervalares. Verificaremos a correlação entre as variáveis "variação dos gastos militares" e "índice de democracia" inicialmente, e posteriormente a correlação entre as variáveis "variação dos gastos militares" e "variação do PIB". Sabemos que a correlação explica como uma variável se comporta quando a outra está variando, visando identificar se existe alguma relação entre a variabilidade de ambas. O coeficiente de correlação quantifica 


\section{Universidade Federal Fluminense \\ Instituto de Estudos Estratégicos}

essa relação em números, não implicando, entretanto, em causalidade entre as variáveis. Não podemos afirmar somente pela correlação que uma variável é a causa da outra, o que não é nosso foco nesta pesquisa, entretanto, a causalidade destes fatores já foi estudada por outros autores, conforme tratado em capítulos anteriores.

Para o estudo de correlação, o primeiro passo é a construção de um gráfico de dispersão "scarlot" com os dois campos. A nuvem de pontos geradas no gráfico nos dará uma boa orientação se as variáveis tem ou não correlação. Percebe-se nos gráficos 7 e 8 que as variáveis estudadas apresentam uma relação linear.

Gráfico 6 - Gráfico de dispersão das variáveis gastos militares e democracia

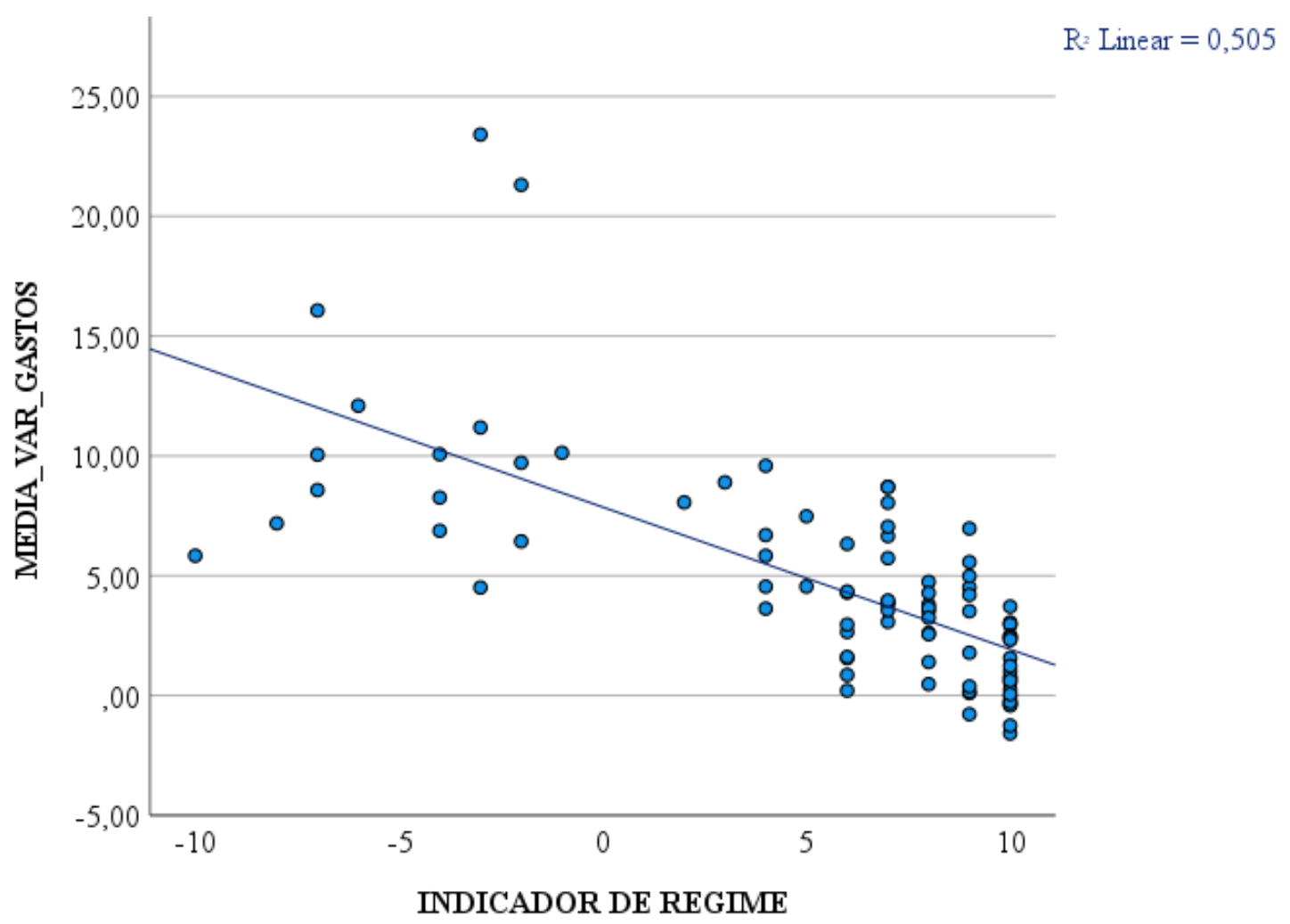


Gráfico 7 - Gráfico de dispersão das variáveis gastos militares e crescimento econômico

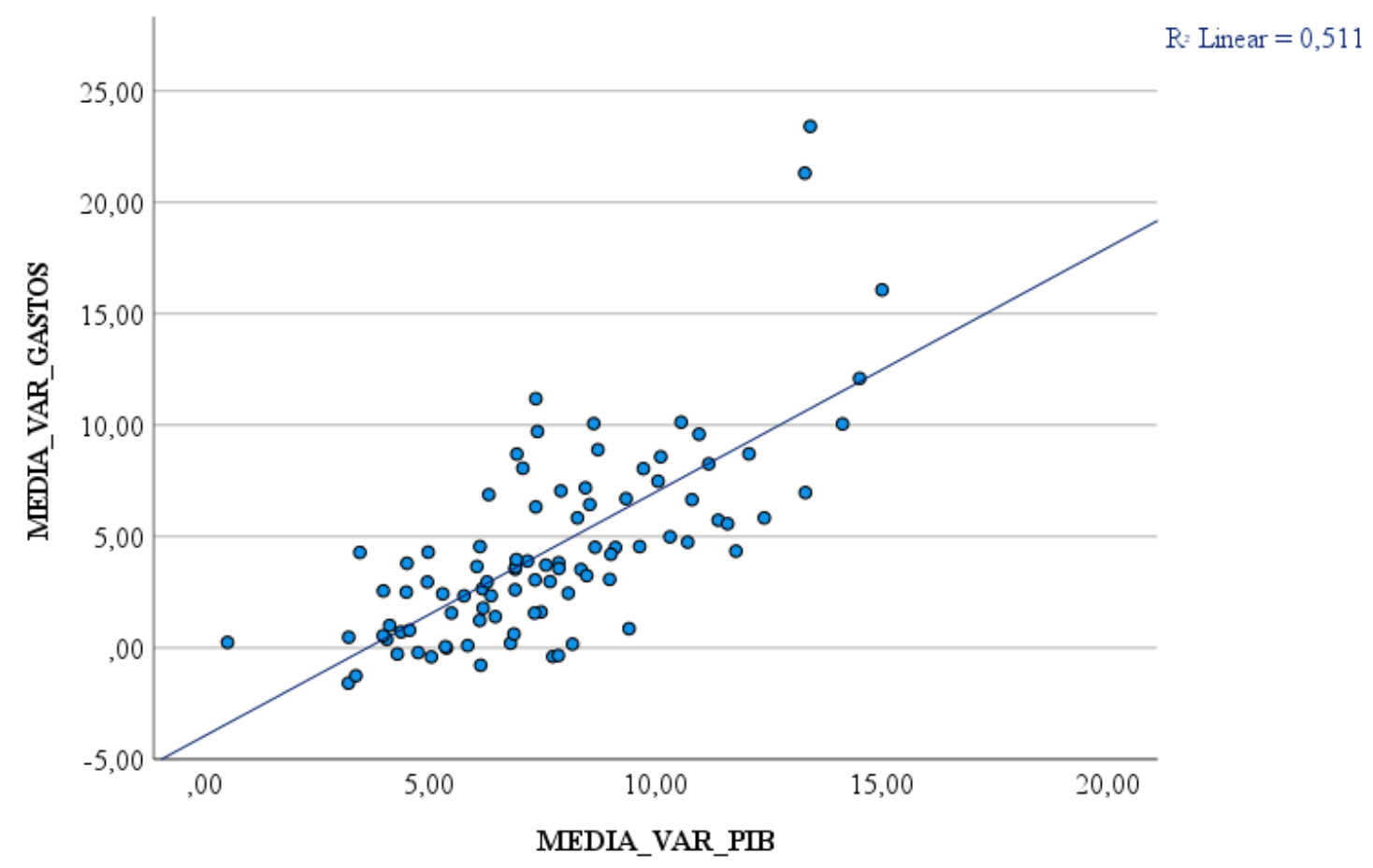

Entretanto, para uma avaliação mais precisa, devemos utilizar um indicador estatístico, neste caso utilizamos o coeficiente linear de Pearson. Este coeficiente varia entre -1 e +1 , de forma que a proximidade de -1 indica que quando um campo cresce, o outro decresce, uma correlação negativa, e a proximidade de +1 indica quando um campo cresce o outro também cresce, uma correlação positiva. A proximidade do coeficiente de zero indica falta de correlação. O grau de correlação pode ser mensurado de acordo com a tabela 5.

Tabela 3 - Regra prática para interpretar o valor de um coeficiente de correlação16

\begin{tabular}{|l|l|}
\hline Valor da Correlação & Interpretação \\
\hline 0,90 a $1,00(-0,90$ a $-1,00)$ & Correlação muito alta positiva (negativa) \\
\hline 0,70 a $0,90(-0,70$ a $-0,90)$ & Correlação alta positiva (negativa) \\
\hline 0,50 a $0,70(-0,50$ a $-0,70)$ & Correlação moderada positiva (negativa) \\
\hline 0,30 a $0,50(-0,30$ a $-0,50)$ & Correlação baixa positiva (negativa) \\
\hline 0,00 a $0,30(0,00$ a $-0,30)$ & Correlação insignificante \\
\hline
\end{tabular}

${ }^{16}$ Fonte: HINKLE, WIERSMA e JURS, 1994, p119, table 5.6. 
Existem atualmente diversos programas para análise estatística, mas nesta pesquisa utilizamos o SPSS (Statistical Package for the Social Science) da IBM, que conforme descrição em seu portal eletrônico, trata-se de "uma plataforma de software de análise estatística avançada, que oferece uma vasta biblioteca de algoritmos de Machine Learning, análise de texto, data science, extensibilidade de software livre, integração com big data e implementação contínua em aplicativos". Desta forma, o SPSS nos permitirá realizar diversos procedimentos de análise estatística, tratamento de banco de dados e construção de gráficos e tabelas, auxiliando no teste das hipóteses.

\section{RESULTADOS}

Tabela 4 - Resultado da análise de Correlação de Pearson entre as variáveis gastos militares e crescimento econômico.

\begin{tabular}{|l|l|c|c|}
\hline \multicolumn{3}{|c|}{ Correlações } \\
\hline \multirow{2}{*}{ MEDIA_VAR_GASTOS } & Correlação de Pearson & 1 & MEDIA_VAR_GASTOS \\
\cline { 2 - 4 } & Sig. (2 extremidades) & &, $715^{\star *}$ \\
\cline { 2 - 4 } & N & 92 & 900 \\
\hline \multirow{2}{*}{ MEDIA_VAR_PIB } & Correlação de Pearson &, $715^{* *}$ & 1 \\
\cline { 2 - 4 } & Sig. (2 extremidades) &, 000 & 92 \\
\cline { 2 - 4 } & N & 92 & 92 \\
\hline \multirow{2}{*}{$*$. A correlação é significativa no nível 0,01 (2 extremidades). }
\end{tabular}

O valor da Correlação de Pearson de 0,715 mostrou que há uma correlação alta e positiva entre as variáveis média de variação de gastos e média de variação de PIB na prova, pois 0,70 >0,715 >0,90.

Desta forma, o resultado obtido no teste de correlação indica que quanto maior o crescimento do PIB do país, maiores serão os incrementos dos gastos militares, validando nossa primeira hipótese. 
Tabela 5 - Resultado da análise de Correlação de Pearson entre as variáveis gastos militares e democracia

\begin{tabular}{|l|l|c|c|}
\hline \multicolumn{5}{|c|}{ Correlações } \\
\hline \multirow{3}{*}{ MEDIA_VAR_GASTOS } & Correlação de Pearson & MEDIA_VAR_GASTOS & INDICADOR DE REGIME \\
\cline { 2 - 4 } & Sig. (2 extremidades) & 1 &,$- 710^{* *}$ \\
\cline { 2 - 4 } & $\mathrm{N}$ & 92 &, 000 \\
\hline \multirow{2}{*}{ INDICADOR DE REGIME } & Correlação de Pearson &,$- 710^{* *}$ & 92 \\
\cline { 2 - 4 } & Sig. (2 extremidades) &, 000 & 1 \\
\cline { 2 - 4 } & $\mathbf{N}$ & 92 & 92 \\
\hline \multirow{2}{*}{ **. A correlação é significativa no nível 0,01 (2 extremidades). }
\end{tabular}

O valor da Correlação de Pearson de $-0,710$ mostrou que há uma correlação alta e negativa entre as variáveis média de variação de gastos militares e o indicador de regime político no teste da hipótese, pois -0,70> $0,710>-0,90$.

Desta forma, o resultado obtido no teste de correlação indica que quanto mais democrático for o país, menores serão os incrementos dos gastos militares, validando nossa segunda hipótese.

\section{CONCLUSÃO}

O objetivo deste artigo foi de elaborar uma análise estatística do comportamento dos gastos militares no século XXI, inicialmente investigando a correlação entre o tipo de regime político e a variação dos gastos militares e posteriormente verificando a relação entre a variação do PIB dos países e a variação dos gastos militares.

Desta forma, tomando como base os estudos já realizados e resultados obtidos por outros autores, as nossas hipóteses propostas foram que quanto maior o crescimento do PIB do país, maiores serão os incrementos dos gastos militares e quanto mais democrático for o país, menores serão os incrementos dos gastos militares.

Utilizando uma base de dados com 92 (noventa e dois) países, 


\section{Universidade Federal Fluminense \\ Instituto de Estudos Estratégicos}

abrangendo países com níveis distintos de desenvolvimento econômico e tipo de regime, abarcando todas as regiões do planeta, foi realizada uma análise estatística de correlação entre as variáveis estudadas, empregando o software SPSS.

Os resultados obtidos pela Correlação de Pearson validaram nossas hipóteses, uma vez que os valores de correlação de 0,715 mostrou que há uma correlação alta e positiva entre as variáveis média de variação de gastos militares e média de variação de PIB e o resultado de $-0,710$ mostrou que há uma correlação alta e negativa entre as variáveis média de variação de gastos militares e indicador de regime político.

\section{REFERÊNCIAS}

ALBALATE, Daniel; BEL, Germà; ELIAS, Ferran. Institutional determinants of military spending. Journal of Comparative Economics, May 2012, Vol.40(2), pp.279-290. DOI: 10.1016/j.jce.2011.12.006

BASTOS, Carlos Pinkusfeld; e MATTOS, Fernando Augusto Mansor de. Crise subprime nos Estados Unidos: a reação do setor público e o impacto sobre o emprego. Revista Tempo do Mundo (RTM): v. 3, n. 2, abr. 2011.

BRAUNER, Jennifer. Military spending and democracy. Working Paper. Birkbeck College, University of London, London, UK, 2014. DOI: 10.1080/10242694.2014.960245.

GARBER, Rogério. Inteligência competitiva de mercado. São Paulo, Editora Letras e Expressões e Madras Editora Ltda., 2001.

GOLDSMITH, Benjamin. "Bearing the Defense Burden, 1886-1989." The Journal of Conflict Resolution, vol. 47, n. 5, 2003.

"Democracy and the Defense Burden: Do Democracies Spend Less on the Military?" Anual Meeting of the American Political Science Association. Philadelphia, 2003.

HEYE, Thomas Ferdinand. Os Determinantes Políticos dos Gastos Militares no Pós-Guerra Fria. Rio de Janeiro, Instituto Universitário de Pesquisas do Rio de Janeiro, 2005. "verificar", Carta Internacional, Brasília, 2015.

HINKLE, Dennis. E., WIERSMA, William e JURS, Stephen G. Applied statistics for the behavioral sciences. 3rd ed. Houghton Mifflin:Company. Boston, 1994.

LIPJHART, Arend. A política comparativa e o método comparativo. Revista de Ciência Política, Rio de Janeiro, v. 18, n. 4, p. 3-19, out. 1975.

NEIRA, Miguel A. Alonso; GONZÁLEZ, Antonio Martínez. Los determinantes del gasto en defensa en la literatura académica de los últimos cincuenta años: una 
revisión de las principales aportaciones y modelos. Hacienda Pública Española / Revista de Economía Pública, 2008, vol. 187, edição 4, 109-139.

WALTZ, Kenneth N. O homem, o estado e a Guerra. Ed. Martins Fontes, 2004.

YILDIRIM, J.; SEZGIN, S. Democracy and Military Expenditure: A Cross-

Country Evidencey. Transition Studies Review (2005), 12 (1): 93-100.

DOI:10.1007/s11300-005-0037-0

ZAVERUCHA, J.; REZENDE, F. How the Military Competes for Expenditure in Brazilian Democracy: Arguments for an outlier. International Political Science Review, v. 30, p. 407-429, 2009. 